\title{
ANÁLISE EXERGÉTICA E AMBIENTAL DO PROCESSO DE OBTENÇÃO DO LICOR DE COZIMENTO KRAFT PARA EXTRAÇÃO DE CELULOSE
}

\author{
H. M. REIS ${ }^{1}$, R. J. SILVA ${ }^{2}$ e J. C. F. MACEDO 3 \\ ${ }^{1}$ Suzano Papel e Celulose \\ ${ }^{2}$ Universidade Federal de Itajubá, Instituto de Engenharia Mecânica \\ ${ }^{3}$ Fibria Celulose S.A. \\ E-mail para contato: rogeriojs@ unifei.edu.br
}

\begin{abstract}
RESUMO - A indústria de extração de celulose branqueada pelo método químico Kraft está com um forte crescimento, devido a qualidade da polpa obtida, além do valor agregado da polpa obtida pelo processo. Porém, tem-se grandes desafios para otimizar os recursos energéticos e avançar ainda mais na preservação ambiental. Para a extração da celulose da madeira é utilizada uma solução contendo hidróxido de sódio $(\mathrm{NaOH})$ e sulfeto de sódio $(\mathrm{Na} 2 \mathrm{~S})$. Para manter a viabilidade econômica e ambiental do processo de extração de celulose Kraft, o licor preto gerado pelo processo de extração de celulose nos digestores é utilizado como combustível na caldeira de recuperação química obtendo-se assim o licor verde que é convertido em licor de cozimento. Este trabalho tem como objetivo efetuar a análise da eficiência, das etapas processuais envolvidas na obtenção do licor de cozimento através da conversão do licor verde, com base na análise exergética, considerando a caustificação do licor e a calcinação.
\end{abstract}

\section{INTRODUÇÃO}

A indústria de extração de celulose e fabricação de papel é um setor indústrial estável que apresenta um ritmo de crescimento forte para os próximos anos porém, há muitos desafios com relação à preservação ambiental e ao potencial energético para o setor. No Brasil e no mundo o momento é de grande investimento no setor devido ao grande aumento no consumo de papéis. Segundo dados da BRACELPA (2014) as exportações brasileiras do setor aumentaram 7,5\% de 2012 para 2013, sendo o aumento de 10,2\% para a exportação de celulose e de 1,0\% para papel. O setor contribuiu com saldo comercial de US\$ 5,313 bilhões em 2013, com produção de celulose acima de 15 milhões de toneladas. O Brasil é o $4^{\circ}$ maior país produtor de celulose do mundo, atrás de EUA, Cina e Canadá. Existe no setor uma estimativa de investimentos de US\$ 12 bilhões para os próximos dez anos.

O processo de extração de celulose pelo método químico kraft é o mais difundido mundialmente e atualmente no Brasil corresponde por cerca de $95 \%$ da celulose extraída da madeira. Nesse método a característica principal é o licor de cozimento utilizado na solubilização da lignina que corresponde a uma solução composta por hidróxido de sódio 


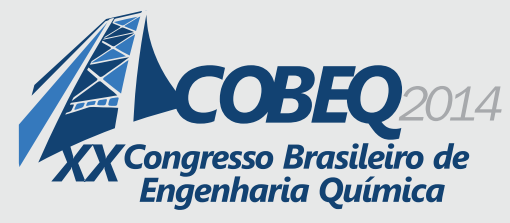

19 a 22 de outubro de 2014
Florianópolis/SC

$(\mathrm{NaOH})$ e sulfeto de sódio $\left(\mathrm{Na}_{2} \mathrm{~S}\right)$. Esse licor, conhecido como licor branco, é utilizado para efetuar o cozimento dos cavacos de madeira nos digestores, onde através de elevação da temperatura e com o tempo de retenção adequado ocorre a solubilização da lignina e a extração da celulose. Durante o processo de digestão dos cavacos de madeira, cerca de $45-55 \%$ da massa de cavacos introduzida saem na forma de liquido chamado de licor preto. O licor preto é convertido nas caldeiras de recuperação química para licor verde que é convertido para licor de cozimento na caustificação para então ser utilizado novamente para a solubilização da lignina nos digestores.

Com base na preocupação cada vez maior no âmbito de melhorias nos processos fabris, principalmente no que diz respeito ao aspecto energético e ambiental, o trabalho proposto tem como objetivo desenvolver a análise exergética das etapas envolvidas para o conversão do licor verde gerado pela caldeira de recuperação química em licor de cozimento que será utilizado pelo digestor para a extração da celulose da madeira de eucalipto. Para o estudo de caso foram empregados os dados de uma planta de extração de celulose e fabricação de papel situada no Estado de São Paulo. A análise foi efetuada a partir do tanque de dissolução do material fundido pela caldeira de recuperação química, passando pela reação de caustificação até a obtenção da cal calcinada pelo forno rotativo de cal. A análise foi realizada através do balanço de massa para os fluxos decorrentes de cada sub-etapa da planta envolvida no processo de preparação do licor de cozimento. Os dados utilizados para a análise foram coletados através do Sistema Digital de Controle Distribuído (SDCD) e do Process Industry (PI) durante o ano de 2012 de uma grande empresa de extração de celulose do estado de São Paulo.

A análise exergética vem demonstrando ser uma ferramenta útil para a análise e avaliação dos componentes em processos produtivos. Esta informação pode ser utilizada para aprimorar o desempenho do processo produtivo, a fim de dar um melhor aproveitamento dos recursos utilizados e ajudar a tomar decisões com respeito ao projeto produtivo e operação dos equipamentos. Essa análise pode fornecer informações para a busca de economia para o processo através de uma visão mais geral e mais profunda no processo.

A contribuição do presente trabalho foi o desenvolvimento do estudo da análise exergética aplicado na preparação in situ do licor de cozimento nas empresas de extração de celulose brasileira. O processo de preparação é complexo envolvendo diversas transformações químicas com equipamentos característicos do setor. Esse processo de preparação torna-se necessária tanto no ponto de vista ambiental, como no ponto de vista econômico.

\section{2 - PROCESSOS DE EXTRAÇÃO DE CELULOSE}

O processo de extração de celulose consiste na transformação da madeira em um material fibroso denominada pasta ou polpa celulósica. Esse processo recebe o nome de polpação sendo definido como o processo de separação das fibras da madeira através da utilização de energia mecânica, térmica ou química ou a combinação entre elas, resultando em uma polpa com características e rendimentos diferenciados (IPT, 1988). No Brasil as madeiras mais utilizadas como matéria prima para a extração da celulose são proveniente das coníferas e das folhosas (Souza, 2008). 


\section{9 a 22 de outubro de 2014 \\ Florianópolis/SC}

A madeira, material lignocelulósico, é composta basicamente por celulose, hemicelulose, lignina e constituições menores. Segundo Fengel (1984), a celulose é o principal componente da parte celular da fibra, é um polissacarídeo linear, constituído por um único tipo de unidade de açúcar ( $\beta$-D-glicopiranose) e de alta massa molecular, alta cristalinidade e muita baixa solubilidade. As hemiceluloses, polissacarídeos constituídas por vários tipos de unidades de açúcar, de cadeia ramificada, baixa massa molecular e sem cristalinidade e solúvel em soluções aquosas. A lignina, um polímero amorfo de composição química complexa, confere firmeza e rigidez ao conjunto de celulose (IPT, 1988). A extração da celulose pode ser efetuada através de diversos processos como: Processo de Alto Rendimento (mecânico convencional (TGW), Termo-Mecânico (TMP), Quimi-Termo-Mecânico (CTMP), Processo Semiquímico e Processo Químico (IPT, 1988).

A polpa obtida pelo processo químico é obtida através da digestão (cozimento) dos cavacos de madeira, com o emprego de produtos químicos (licor de cozimento). O processo mais difundido mundialmente é o processo kraft (também conhecido como processo sulfato).

O licor de cozimento utilizado no processo kraft é uma solução aquosa de hidróxido de sódio e sulfeto de sódio com um pH de 13-14 onde a deslignificação ocorre através da ação sobre as ligações éter da molécula de lignina liberando grupos hidroxila fenólicos, que favorecem a dissolução da lignina no meio alcalino. Nesse processo grande parte da celulose da madeira é preservada e as hemiceluloses dissolvidas reprecipitam dando à fibra alta resistência mecânica. A lignina é fortemente hidrolisada e possui uma massa molar baixa (Hernández, 2007). O objetivo do processo kraft é a separação da lignina das cadeias de carboidratos (celulose e hemicelulose) com o mínimo de degradação das fibras. A lignina é uma substância amorfa, de natureza aromática e muito complexa, e faz parte da parede celular e da lamela média dos vegetais que confere rigidez à parede celular, sendo responsável pela ligação entre as fibras da madeira, além de proteger os tecidos contra o ataque de microorganismos (Fengel \& Wegener, 1984). Ao contrário da celulose, que tem uma estrutura bem definida e conhecida, as ligninas são biopolímeros tridimensionais amorfos com uma estrutura molecular complexa e variável que depende da espécie vegetal, localização, idade da planta, estação do ano, etc. Sabese que as ligninas são constituídas por duas unidades básicas guaiacil (G) e sinapil (S) (Adler 1977, Glaser, 1981, Sarkanen, 1971 apud Hernández , 2007).

\section{EFICIÊNCIA EXERGÉTICA}

A eficiência exergética é a relação entre a variação da exergia desejada e o consumo de exergia necessária ao processo. O principal propósito de uma análise exergética é estimar o rendimento termodinâmico de um sistema energético e a eficiência dos componentes deste ao quantificar com a maior exatidão a geração de entropia do sistema (Kwak et al. 2003). A eficiência exergética representa a porcentagem de exergia dos recursos que se encontram nos produtos de um sistema térmico ou em alguns de seus componentes. Portanto, a eficiência exergética dá um inequívoco critério para avaliar o desempenho de um sistema térmico e de seus componentes. 
Dois parâmetros importantes para a definição da eficiência exegértica estão relacionados com os recursos (F) e os produtos (P) do sistema térmico estudado. Segundo Tsatsaronis (1993), os fluxos que pertencem a fonte de exergia se denominam recursos $(\mathrm{F})$ necessários para a obtenção de um determinado produto $(\mathrm{P})$. Assim, a eficiência exergética $(\Psi)$ será dada pela Equação 1.

$$
\psi=\frac{B_{P}}{B_{F}}
$$

A Figura 3 representa o ciclo de preparação do licor de cozimento utilizado no processo químico kraft de extração de celulose. Neste trabalho serão analisados os processos a partir dissolução do material fundido gerado nas caldeiras de recuperação química no tanque dissolvedor (1). Em seguida, o licor verde bruto e filtrado em filtros pressurizados para a remoção das impurezas (2), sendo as impurezas (dregs) filtrada em filtro rotativo à vácuo para elevar a consistência (3), o licor verde filtrado é encaminhado para reação de caustificação nos reatores (4). O licor branco bruto obtido passa pelo processo de filtração pressurizada para a remoção da lama de cal (5), a lama separada do licor branco passa por processo de lavagem e aumento de consistência (6). A lama obtida é calcinada no forno de cal (7), sendo que os gases de combustão do forno tem o controle ambiental através da passagem no precipitador eletrostático (8) e pelo lavador de gases (9) antes de serem descartados para a atmosfera. As condições de operação para o trabalho proposto encontram-se resumidas na Figura 1.

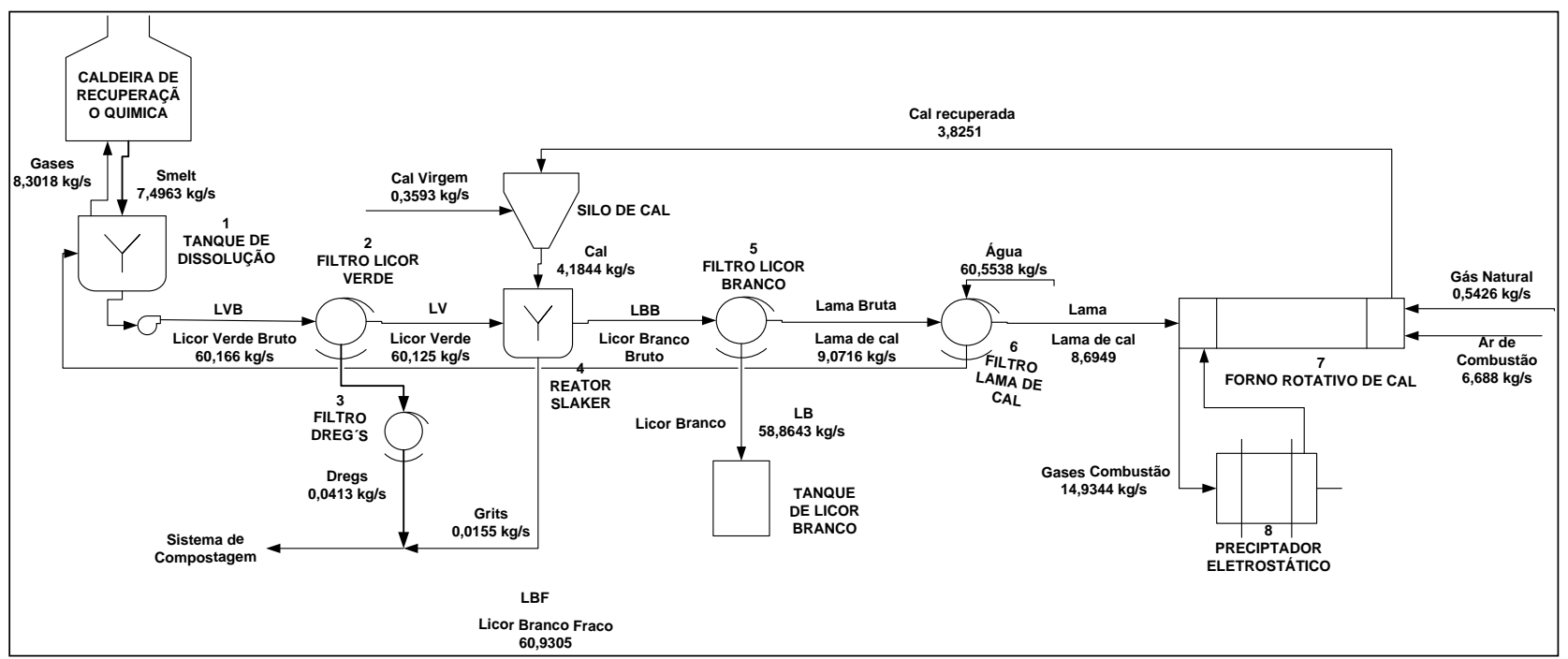

Figura 3 - Volume de controle estudado para a preparação do licor de cozimento

\subsection{PREPARAÇÃO DO L ICOR DE COZIMENTO}

Para a preparação do licor de cozimento (licor branco) utilizado no processo de cozimento dos cavacos pelo digestor, o licor verde bruto obtido na diluição do material fundido na caldeira de recuperação é bombeado para o setor de caustificação passando: 1) pelo processo de filtragem, para a separação de impurezas contidas no licor provenientes da combustão do licor 
preto nas caldeiras de recuperação química, conhecidas como dregs, obtendo se assim o licor verde filtrado (LVF); 2) em seguida o licor verde recebe a adição de óxido de cálcio através da dosagem de cal calcinada ou cal virgem ocorrendo assim a reação de caustificação, ou seja, a obtenção do licor branco bruto; 3) em seguida o licor branco bruto é filtrado para a remoção da lama de carbonato de sódio formada durante a reação de caustificação. Apresenta-se na Figura 2 o volume de controle do processo de preparação do licor branco.

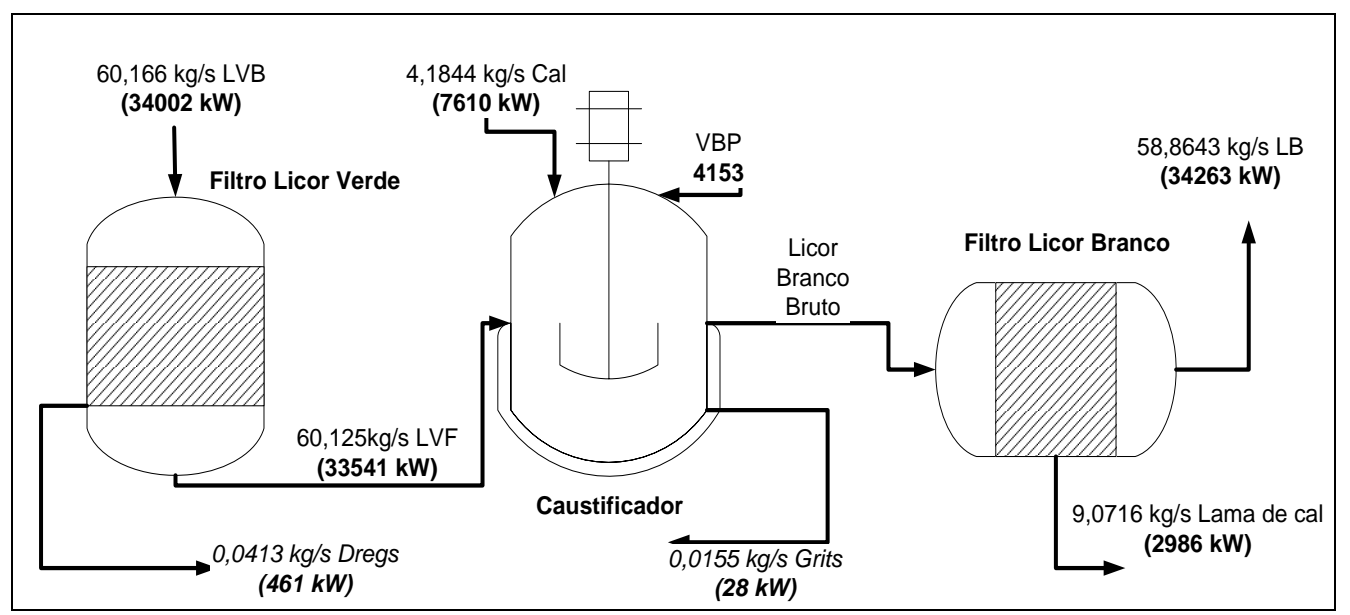

Figura 2 - Fluxos de massa e energia que atravessam o volume de controle da conversão do licor verde bruto em licor de cozimento (Licor Branco - LB).

\subsection{EXERGIA DO LICOR DE COZIMENTO}

A entalpia física, entropia e exergia foram calculadas a partir do estado determinado pela temperatura ambiente $\left(\mathrm{T}_{0}\right)$ e pressão $\left(\mathrm{p}_{0}\right)$ sem qualquer alteração da composição química da substância considerada. A Equação 2 representa exergia física específica:

$$
\mathrm{b}_{\mathrm{ph}}=h-T_{o} s
$$

A exergia física pode ser calculada em parcelas dependendo da pressão e outra dependendo da temperatura. A parte dependente da temperatura corresponde à variação de entalpia e entropia na pressão p 0 (Van Wylen et al, 2005), sendo representada pela Equação 3.

$$
\mathrm{b}_{\mathrm{ph}}=\dot{m}\left(\Delta h-T_{o} \Delta s\right)
$$

Onde $\dot{m}$ é a vazão mássica $(\mathrm{kg} / \mathrm{s})$.

Para obter os valores da variação de entalpia, $\Delta \mathrm{h}$, e da entropia, $\Delta \mathrm{s}$, pode-se utilizada as Equações 4 e 5, cujos coeficiente de $\mathrm{cp}(\mathrm{T})$ foram reportados por Perry et al (1999).

$$
\Delta h=\int_{298,15}^{T} c p(T) d T
$$

$$
\Delta s=\int_{298,15}^{T} \frac{c p(T)}{T} d T
$$


Quando o sistema atinge um equilíbrio térmico e mecânico, ainda é possível obter trabalho adicional até alcançar o equilíbrio químico com o estado de referência. A exergia química é a quantidade máxima de trabalho obtida quando a substância é trazida do estado do ambiente para o estado de equilíbrio termodinâmico (estado morto), por processos que envolvem transferência de calor, sistemas reativos, e intercambio de substâncias apenas com o meio ambiente, sistemas não reativos (Kotas, 1985). Em sistemas reativos obtém-se trabalho através da energia liberada em reações químicas. Nos sistemas não reativos o trabalho mecânico pode ser obtido através da difusão dos componentes iniciais até o estado de equilíbrio com o entorno. Exergia química expressa o conteúdo de exergia da substância na temperatura e na pressão ambiente através da diferença do potencial químico entre os dois estados (Szargut, 2005).

A exergia química padrão ou a de compostos químicos ou elementar pode ser calculada por meios do balanço de exergia (Szargut, 2005) através da Equação 16.

$$
b_{c h}^{0}=-\Delta_{r} G^{0}+\sum_{k} B^{0} c h k-\sum_{j} B^{0} c h j
$$

Sendo:

$$
\begin{aligned}
& \Delta_{r} G^{0}=\text { energia livre de Gibbs padrão para a reação } \\
& \sum_{k} B^{0}{ }_{c h k}, \sum_{j} B^{0}{ }_{c h j}=\text { soma da exergia química padrão dos reagentes e dos produtos. }
\end{aligned}
$$

A diluição do smelt para a obtenção do licor verde bruto é efetuado através da adição de líquido de lavagem chamado de licor branco fraco (LBF). Esse licor é proveniente do setor da caustificação sendo oriundo da lavagem da lama de cal, filtração dos dregs e recuperação de transbordo diversos no setor. O licor de cozimento, licor branco bruto, obtido na reação de caustificação se encontra em fase heterogênea devido a presença da lama de carbonato de cálcio precipitada durante a reação. O processo de separação da lama formada ocorre através de processo de filtração efetuado nos filtros de licor branco. O licor branco filtrado é destinado ao setor de polpação para ser utilizado no digestor para efetuar o cozimento dos cavacos para a extração da celulose. Na Figura 3, o diagrama de Grassman apresenta todos os fluxos que fazem parte do processo de obtenção do licor de cozimento pelo processo químico kraft através dos volumes de controle estudados.

Para a determinação da eficiência exergética envolvida na reação de caustificação do licor verde tem-se como Produto desejado o Licor de cozimento, chamado de Licor Branco (LB) e como Recursos o Licor Verde (LV), o óxido de cálcio (cal), o vapor de baixa pressão (VBP) e a Energia Elétrica (EE). O cálculo da eficiência exergética para a reação de caustificação foi efetuado com a Equação (7), portanto, a exergia envolvida no volume de controle é:

$$
\begin{gathered}
\psi_{\text {CAUST }}=\frac{\text { exergia } \mathrm{LB}}{\text { exergia } \mathrm{LV}+\text { exergia cal }+ \text { exergia } \mathrm{VBP}+\mathrm{EE}} \\
\psi_{\text {CAUST }}=\frac{34263}{33541+7611+4154+400} \quad \psi_{\text {CAUST }}=74,96 \%
\end{gathered}
$$




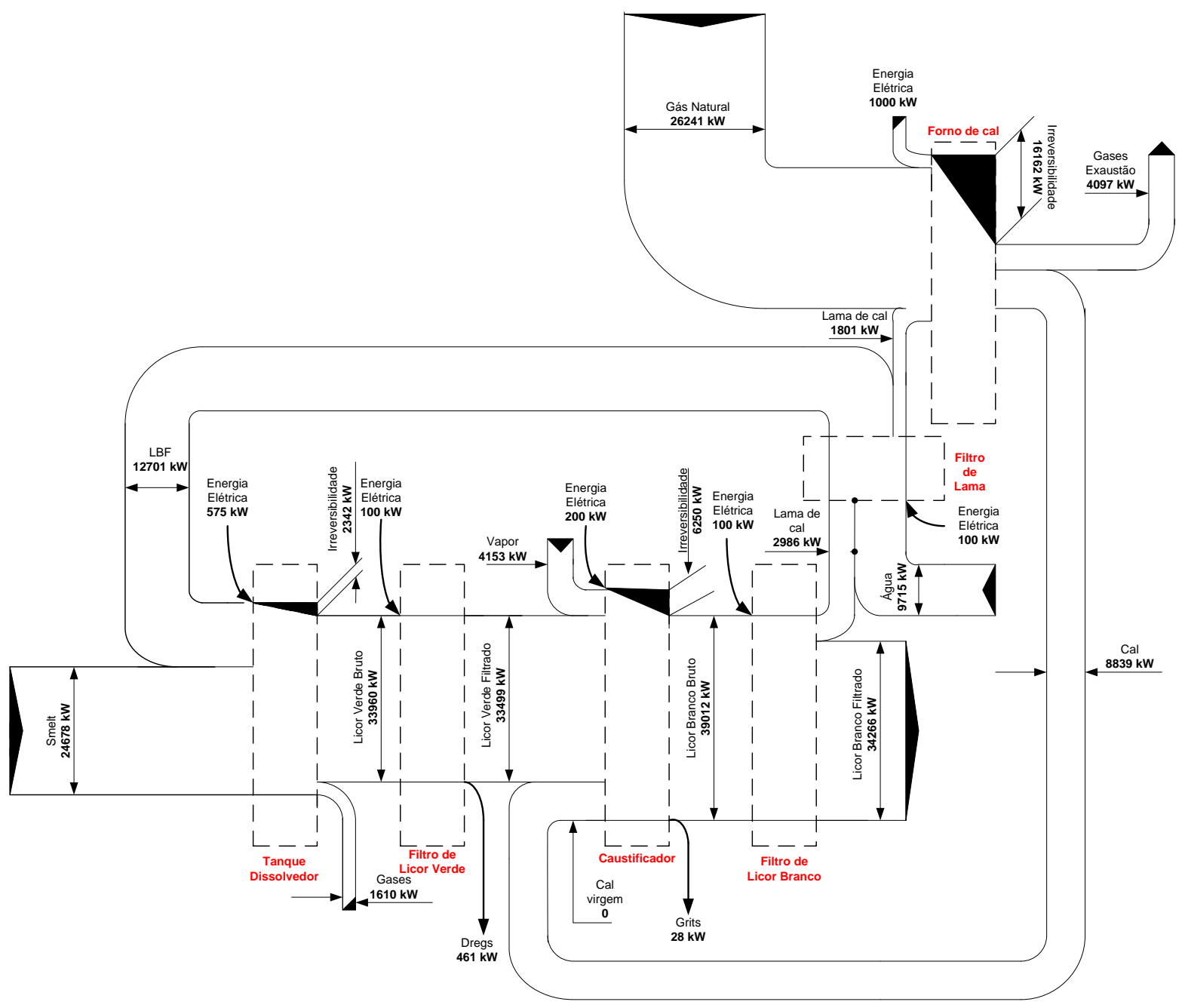

Figura 4 - Diagrama de Grassmam representando todas as etapas e os fluxos de exergia $(\mathrm{kW})$ do processo de preparação do licor de cozimento Kraft estudado.

\section{CONCLUSÕES}

Um dos insumos mais importantes para a contribuição dos custos para o processo fabril de extração de celulose pelo método químico kraft é o licor de cozimento. A boa performance das sub-etapas envolvidas no processo de obtenção do licor tem influência direta na qualidade, na quantidade e, consequentemente, no custo do produto obtido.

A análise exergética permite distinguir a relação entre irreversibilidade, calor, trabalho e fluxo de energia de um sistema, podendo indicar possíveis formas de melhorias para esses processos, identificando os componentes com maior destruição de exergia e avaliando as 
eficiência, em cada etapa do processo. A aplicação desse conceito fornece informações para o planejamento de longo prazo de uma gestão eficiente dos recursos.

Do ponto de vista ambiental, as empresas de extração de celulose pelo método químico kraft adotam medidas de controle a fim de buscar a redução nas emissões atmosféricas, equipamento mais eficientes e destinos mais nobres para os resíduos sólidos. Hoje em dia, as empresas desse tipo de processo reduzem o odor gerado através de coleta, lavadores do tipo scrubber, melhores práticas no processo de produção e a incineração dos gases em incineradores, caldeiras ou fornos.

\section{REFERÊNCIAS}

BRACELPA - Associação Brasileira de Celulose e Papel. Conjuntura Bracelpa. Publicação Mensal da Associação Brasileira de Celulose e Papel, V. 64, Março, 2014.

FENGEL, D. and WEGENER, G. Wood Chemistry, Ultrastructure, Reactions, Berlin and New York, Walter de Gruyter \& Co, 613 p., 1984.

HERNÁNDEZ, J. A. Lignina Organosolv de Eucalyptus Dunnii Maiden, Alternativa para a síntese de adesivos de poliuretano para madeira. 2007. 93 f. Tese (Doutorado em Engenharia Florestal). Engenharia Florestal do Setor de Ciências Agrárias. Universidade Federal do Paraná.

IPT - Instituto de Pesquisas Tecnológica do Estado de São Paulo; Escola SENAI "Theobaldo De Nigris" - Departamento Regional de São Paulo. Celulose e Papel - Tecnologia de fabricação da pasta celulósica. Vol 1. 2ed. São Paulo-SP, 1988.

KWAK, H.Y.; KIM, D.J. et al. Exergetic and thermoeconomic analyses of power plants. Energy, v.28, p.343-360. 2003.

KOTAS, T. J. The exergy method of thermal plant analysis. London: Butherworths. 1985. 293p.

PERRY, R.H.; GREEN, D.W,; MALONEY, J.O. Perry's Chemical Engineers Handbook, 7rd ed. McGraw-Hill Companies,Inc.1999.

SOUZA, A. H. C. B. Guia técnico ambiental da indústria de papel e celulose. CETESB, São Paulo-SP, 49 páginas, 2008.

SZARGUT, J. Exergy method. Techinical and Ecological Applications. WIT Press. 2005.

TSATSARONIS, G. Thermoeconomic Analysis and Optimization of Energy Systems. Prog. Energy Combusti. Sci. 1993.

\section{AGRADECIMENTOS}

Os autores agradecem à FAPEMIG, CAPES e PET-SESu/MEC, pelo apoio financeiro. 